less aggressive measures may, in our opinion, hold the solution to this complication in many cases. We would therefore recommend the systemic use of enoximone to treat IMA hypoperfusion.

\section{REFERENCES}

1. Sarabu MR, McClung JA, Fass A, Reed GE. Early postoperative spasm in the left internal mammary artery bypass grafts. Ann Thorac Surg 1987;44:195200.

2. Jones EL, Lattouf OM, Weintaub WS. Catastrophic consequences of internal mammary artery hypoperfusion. J Thorac Cardiovasc Surg 1989;98:902-7.

3. Izzat MB, West RR, Ragoonanan C, Angelini GD. Effect of systemic vasodilators on internal mammary artery flow: implications for postoperative treatment after myocardial revascularization. J THORAC CARDIOVASC SURG 1994;108:82-5.

\title{
NARROWING OF THE AORTIC ANULUS IN VALVE-SPARING ANNULOAORTIC GRAFTING
}

\author{
Kiyoyuki Eishi, MD, ${ }^{\text {a }}$ Yoshitsugu Kitoh, MD, ${ }^{\text {a }}$ Shinichi Takamoto, MD, ${ }^{a}$ Sunao Watanabe, MD, ${ }^{\mathrm{b}}$

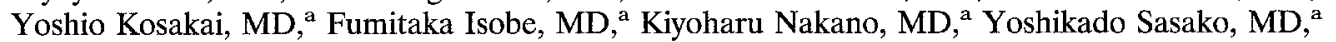 \\ Junjiro Kobayashi, MD, ${ }^{a}$ and Yasunaru Kawashima, MD, ${ }^{a}$ Osaka and Sapporo, Japan
}

In patients with aneurysm of the ascending aorta associated with aortic regurgitation (AR), replacement of the vessel with a composite graft including a prosthetic valve has been widely performed. ${ }^{1-3}$ Valve-sparing annuloaortic grafting for patients with annuloaortic ectasia ${ }^{4}$ associated with AR was reported by David and Feindel ${ }^{5}$ in 1992. Although this operation is an alternative for patients who have annuloaortic ectasia and AR with normal leaflets, postoperative valvular function is still a subject of controversy. ${ }^{6}$ We treated a patient in whom the aortic anulus became narrower after valve-sparing annuloaortic grafting, resulting in aortic stenosis and residual AR.

Case report. A 43-year-old woman had had severe chest pain on mild effort since May 1994, when she had given birth. The woman had no history of rheumatic fever, recent fever, or infection and no family history of Marfan's syndrome. She was small (142 cm in height, 46 $\mathrm{kg}$ in body weight), and a physical examination showed no symptoms of Marfan's syndrome. Echocardiography revealed dilatation of the base of the ascending aorta (49 $\mathrm{mm}$ ) and grade $4 / 4 \mathrm{AR}$ with mild prolapse of the right coronary cusp. Catheterization also showed dilatation of the ascending aorta, Sellers's grade III AR with a blood pressure of $175 / 75 \mathrm{~mm} \mathrm{Hg}$, and normal coronary arteries.

Median sternotomy was carried out with the use of neuroleptanalgesia with the patient in the supine position. Pump perfusion was initiated with cannulas in the ascending aorta and both cavae. After crossclamping and insertion of a venting cannula into the right superior pulmo-

From the Department of Cardiovascular Surgery, National Cardiovascular Center, ${ }^{a}$ Osaka, Japan, and Hokko Cardiovascular Hospital,', Sapporo, Japan.

J Thorac Cardiovasc Surg 1995;110:870-2

Copyright (C) 1995 by Mosby-Year Book, Inc.

$0022-5223 / 95 \$ 5.00+0 \quad \mathbf{1 2 / 5 4 / 6 3 9 9 1}$ nary vein, a transverse aortic incision was made, which was then extended deep into the base of the noncoronary sinus. Cold St. Thomas' Hospital cardioplegic solution, $700 \mathrm{ml}$, was given directly into both coronary orifices. The proximal ascending aorta was dissected circumferentially down to a level immediately below the lowest portion of the aortic valve. All three sinuses of Valsalva were excised, with 5 to $7 \mathrm{~mm}$ of the arterial wall left attached to the aortic valve and a small button of the arterial wall remaining around the left and right coronary arteries. Thirteen interrupted horizontal mattress sutures of 4-0 Prolene polypropylene (Ethicon, Inc., Somerville, N.J.) were passed from inside to outside the left ventricular outflow tract immediately below the aortic leaflets. The leaflet height was $14 \mathrm{~mm}$, and a $24 \mathrm{~mm}$ Hemashield graft (Meadox Medicals, Inc., Oakland, N.J.) was selected (the expected diameter of the anulus was $19 \mathrm{~mm}$, which was calculated as one third longer than the leaflet. ${ }^{5}$ The patient's anulus was $24 \mathrm{~mm}$. The previously placed horizontal mattress sutures were then passed through the end of the graft. The aortic valve was placed inside the graft and all sutures were tied outside. The proximal end of the graft was sutured to surrounding tissue of the anulus with 4-0 Prolene suture for hemostasis. The arterial wall above the commissures was secured to the graft inside with pledget-supported 4-0 Prolene sutures. Next, starting at the lowest level of the right coronary cusp, a remnant of the arterial wall was sutured to the graft with a continuous 4-0 Prolene suture from inside and was continued to the left and the noncoronary cusp remnants. At this point, the anulus shrank to $15 \mathrm{~mm}$ because the sutures had been tied tightly around it, and additional plication of the right coronary cusp was required to relieve a severe prolapse. Competence of the aortic valve was checked by filling the graft with saline solution. The coaptation looked complete after the plication. The coronary arteries were reimplanted in the graft with a 

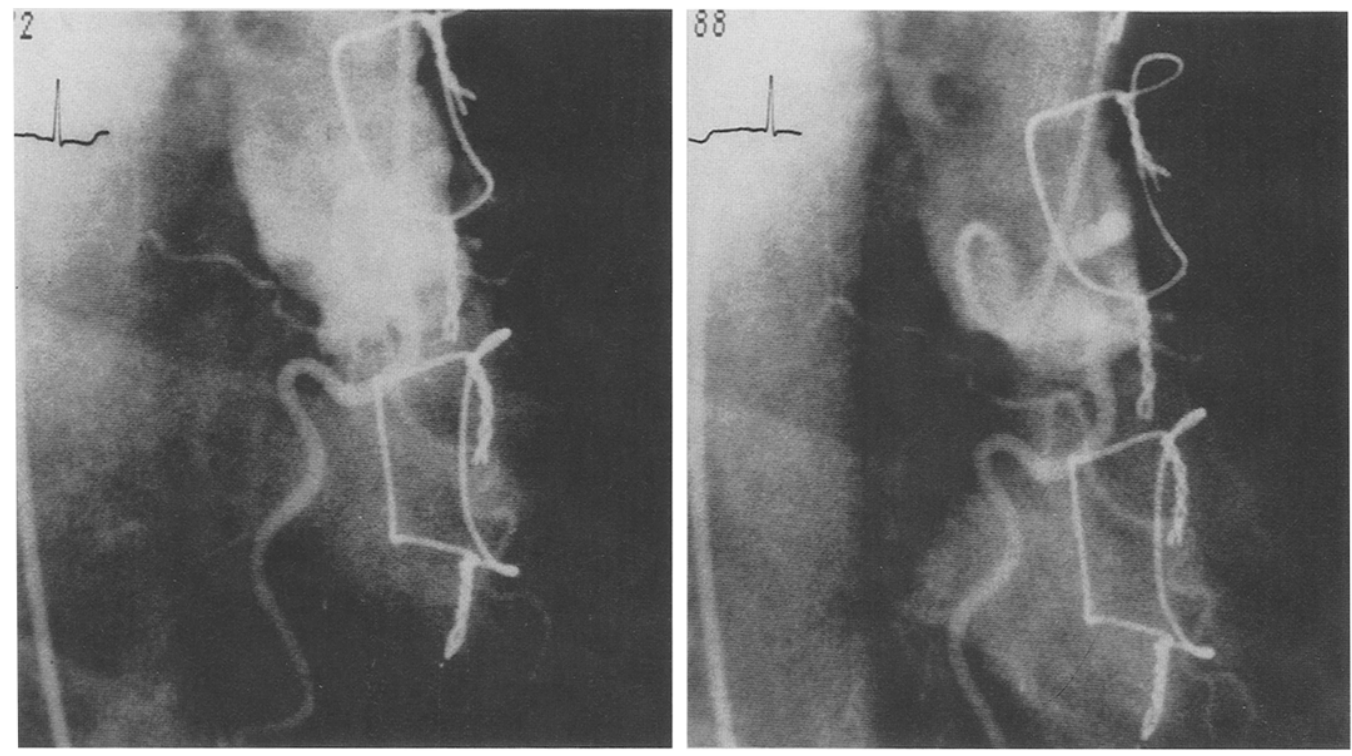

Fig. 1. Postoperative catheterization revealed narrowing of the aortic anulus $(15 \mathrm{~mm})$ with a $24 \mathrm{~mm} \mathrm{Hg}$ transvalvular pressure gradient and Sellers's grade II AR. The graft was a $24 \mathrm{~mm}$ Hemashield graft. Postoperative aortography during diastole is on the left and systole is on the right.

continuous 4-0 Prolene suture reinforced by felt. The upper end of the graft was then anastomosed to the ascending aorta. After release of the crossclamp, a transesophageal echocardiogram showed good coaptation without significant AR. Weaning from cardiopulmonary bypass was uneventful and the patient was transferred to the intensive care unit in good condition. Her subsequent postoperative course was uneventful, and she was discharged in good condition. Postoperative catheterization, however, revealed narrowing of the aortic anulus $(15 \mathrm{~mm})$ with a $24 \mathrm{~mm} \mathrm{Hg}$ transvalvular pressure gradient and Sellers's grade II AR (Fig. 1).

Comment. Composite graft replacement is a useful and reliable procedure for patients with annuloaortic ectasia associated with AR ${ }^{1-3}$ Its only disadvantage is the use of a prosthetic valve. AR associated with annuloaortic ectasia is caused by dilatation of an anulus or sinuses, the leaflets usually being normal. Sarsam and Yacoub, ${ }^{7}$ in 1993, reported a procedure similar to David and Feindel's valve-sparing technique. Their technique remodels the aortic valve anulus by grafting the sinus of Valsalva for patients with AR. Although this procedure is another option for patients who have annuloaortic ectasia with normal leaflets, postoperative valvular function is still the subject of controversy ${ }^{6}$ : Can remodeling of the aortic valve anulus control the AR completely in patients with normal aortic leaflets, and how should the appropriate diameter of the anulus be determined?

Between August and October 1994, we performed valve-sparing annuloaortic grafting in four patients with annuloaortic ectasia and AR. In the third of these patients, whose case is discussed here, AR recurred as a result of shrinkage of the anulus. In the last patient, a bougie of appropriate size was positioned inside the anulus before the sutures were tied to prevent narrowing.

Another problem is whether prolapse of the right coronary cusp, which was mild before the operation, was magnified by narrowing of the anulus in this patient. Because a slight prolapse of the aortic cusp is commonly noticed on echocardiograms in patients with annuloaortic ectasia and AR, indications for valve-sparing annuloaortic grafting should be investigated in larger series.

All four patients in our series returned to New York Heart Association class I or II, and AR was well controlled in all except this one patient. Although valvesparing annuloaortic grafting is useful for patients with annuloaortic ectasia associated with $\mathrm{AR}$, more care should be taken to prevent narrowing of the aortic anulus and residual AR.

\section{REFERENCES}

1. Bentall $\mathbf{H}$, DeBono A. A technique for complete replacement of the ascending aorta. Thorax 1968;23:338-9.

2. Cabrol C, Pavie A, Gandjbakhch I, et al. Complete replacement of the ascending aorta with reimplantation of the coronary arteries. J THORAC CARdiovasC SuRg 1981;81:309-15.

3. Kawazoe K, Eishi K, Kawashima Y. New modified Bentall procedure: Carrel patch and inclusion technique. Ann Thorac Surg 1993;55:1578-9.

4. Ellis PR, Cooley DA, De Bakey ME. Clinical consid- 
erations and surgical treatment of annulo-aortic ectasia. J Thorac Cardiovasc Surg 1961;42:363-70.

5. David TE, Feindel CM. An aortic valve-sparing operation for patients with aortic incompetence and aneurysm of the ascending aorta. J THORAC CARDIOVASC SURG 1992;103:617-22.
6. Borst HG, Gott VL, Griepp RB, Kouchoukos NT, Miller DC. Panel Discussion I. J Cardiovasc Surg 1994;9:516-24.

7. Sarsam MAI, Yacoub M. Remodeling of the aortic valve anulus. J Thorac CARdiovasc SuRg 1993;105: 434-7.

\title{
NONSYNDROME FAMILIAL ATRIAL MYXOMA IN TWO GENERATIONS
}

\author{
B. Reddy Dandolu, MD, K. S. Iyer, MD, B. Das, MD, and P. Venugopal, MD, New Delhi, India
}

Since the first report of a family with cardiac myxomas in 1971 by Krause and associates, ${ }^{1} 17$ such families have been reported worldwide. ${ }^{2}$ Among these there are only two cases in which four members in a single family had cardiac myxomas. ${ }^{2,3} \mathrm{~A}$ high percentage of families also have noncardiac cutaneous and endocrine manifestations, which are termed Carney syndrome. ${ }^{4}$ We report a case in which four members in a family are involved without any of the extracardiac features described in the syndrome.

A 17-year-old girl (B-F6) was brought to our emergency department with signs suggestive of pulmonary edema in November 1991. On a review of her records we found that she was being treated with decongestive therapy in our cardiology clinic for symptoms of dyspnea and palpitation with a clinical diagnosis of mitral stenosis of rheumatic origin. An echocardiogram performed immediately showed a large myxoma in the left atrium prolapsing in and out of the mitral valve. After her condition was clinically stabilized, an electrocardiogram-gated magnetic resonance imaging study with contrast medium was performed. This confirmed the diagnosis of left atrial myxoma arising from the interatrial septum. She was immediately taken to the operating room. With the aid of cardiopulmonary bypass and cardioplegic arrest, a right atriotomy was performed and the interatrial septum from which the stalk originated, along with the tumor, was excised with a $1 \mathrm{~cm}$ margin. The defect was closed with a Dacron patch. A thorough search in all chambers of the heart did not reveal multiple tumors. The tumor was 10 by $8 \mathrm{~cm}$ and did not deviate from the usual sporadic myxoma pattern by either gross or histopathologic examination. The excised tumor was placed in a glass container filled with saline and was subjected to magnetic resonance imaging with tissue spectroscopy. These images also did not show any variation when compared with those of a

From the Department of Cardiothoracic Surgery, All India Institute of Medical Sciences, New Delhi, India.

J Thorac Cardiovasc Surg 1995;110:872-4

Copyright (C) 1995 by Mosby-Year Book, Inc.

$0022-5223 / 95 \$ 5.00+0 \quad \mathbf{1 2 / 8 / 5 8 9 5 5}$ sporadic myxoma. The patient made an uneventful postoperative recovery.

On investigating the family history we learned that her elder brother (B-M2) underwent a similar excision of left atrial myxoma at our institute in 1979 at the age of 14 years when he presented with left hemiparesis and seizures after a cerebral embolism. He is currently doing well without any evidence of recurrence and taking only antiepileptic medication. On further inquiry we learned that the eldest of the siblings (B-M1) had died suddenly while running when he was a 12 -year-old boy in 1968. He had a history of dyspnea on exertion for a short period before his death and proper medical attention was not sought. No autopsy was performed.

At this point we decided to investigate the whole family. When we did an echocardiogram on the mother (A-F1) and father (A-M1) of those patients, the 55-year-old mother was found to have a biatrial myxoma with the stalks growing from either side of the interatrial septum. She was completely free of symptoms. The father (A-M1) had a normal study. In the second generation of the three living elder sisters of the operated patients two, (B-F3 and B-F4) had a normal study. The third sister (B-F5) refused to undergo any kind of medical evaluation for social reasons. In the third generation the two children of (B-F3) had a normal study. The two third-generation children of (B-F5) could not be evaluated along with their mother. None of the other second-generation subjects have children. A thorough physical examination was performed in all members of the family with emphasis on any skin or mucocutaneous pigmentation, cutaneous or breast tumors, and any clinical signs of endocrine hyperactivity. Serum levels of various adrenocortical, pituitary, and thyroid hormones were done. We could not find any evidence of Carney syndrome in any member of the family (Fig. 1).

The mother (A-F1) was subjected to contrast magnetic resonance imaging with tissue spectroscopy (Fig. 2), which confirmed the diagnosis of biatrial myxoma. She was taken to the operating room. Cardiopulmonary bypass was established with bicaval cannulation. The right atrium was opened, a 3 by $3 \mathrm{~cm}$ myxoma arising from the posterior wall of the right atrium was excised 